\title{
CERTOS SENTIDOS DE BIBLIOTECA ESCOLAR: EFEITOS DE REPETIÇÃO E DESLOCAMENTO
}

\author{
Ludmila Ferrarezi* \\ Lucília Maria Sousa Romão**
}

Resumo: A partir do embasamento teórico-analítico da Análise do Discurso de linha francesa, especialmente os conceitos propostos pelo filósofo Michel Pêcheux, nós investigamos quais sentidos foram mobilizados na constituição dos discursos sobre a biblioteca escolar que circulam em três documentos oficiais, elaborados pelos órgãos de classe da Biblioteconomia e disponibilizados na Internet. Para tanto, nós apresentamos inicialmente os conceitos de memória, ideologia, formação discursiva, formação imaginária e heterogeneidade, que nos ajudaram a investigar o funcionamento discursivo presente em nosso corpus. Nele, observamos, através de nossas análises, como a memória discursiva faz com que alguns sentidos já-ditos sobre a biblioteca escolar sejam atualizados e, ao mesmo tempo, como eles podem ser rompidos, instalando o diferente.

Palavras-chave: Discurso. Memória. Biblioteca escolar. Biblioteconomia.

\section{NAS TRAMAS DA MEMÓRIA: UM INÍCIO DE SENTIDOS SOBRE A BIBLIOTECA ESCOLAR}

O tempo é uma superfície obliqua e ondulante que só a memória é capaz de fazer mover e aproximar. (SARAMAGO, 2003, p. 168).

\footnotetext{
* Mestre em Linguística e doutoranda em Ciências na Faculdade de Filosofia, Ciências e Letras de Ribeirão Preto - FFCLRP/USP. Email: ludmila.ferrarezi@pg.ffclrp.usp.br.

** Faculdade de Filosofia, Ciências e Letras de Ribeirão Preto - FFCLRP/USP. Professora do Programa de Pós-graduação em Psicologia e da Graduação em Ciências da Informação e da Documentação. Livre-docente pela FFCLRP/USP. Email: luciliamsr@uol.com.br.
} 
Nos últimos anos, temos nos dedicado a investigar como se dá a produção e circulação de sentidos sobre a biblioteca escolar, analisando, para tanto, diferentes corpora, dentre os quais destacamos vários documentos oficiais em que observamos (FERRAREZI, 2007, 2010) um funcionamento discursivo semelhante, pelo qual pudemos flagrar o retorno da memória, de sentidos já colocados em discurso. Por uma rede de paráfrases, circulam sentidos que normatizam o que e como a biblioteca escolar deve ser, ou seja, as recomendações acerca de suas funções, objetivos e funcionamento, que constituem, pela repetição, um préconstruído aparentemente óbvio e natural, marcando o que pode ser dito sobre a biblioteca escolar, quais aspectos devem ser considerados, deixando latente uma série de outros discursos que, sob condições sócio-históricoideológicas diversas, poderiam ser atualizados. Partindo dessas observações gerais, investigaremos, neste artigo, como a biblioteca escolar é discursivizada em três documentos dos órgãos de classe da Biblioteconomia, seguindo, para isso, as pistas do funcionamento da memória e da ideologia, a fim de ampliarmos o escopo das questões já discutidas em trabalhos anteriores. Para tanto, apresentaremos, inicialmente, alguns conceitos fundamentais para a Análise do discurso de linha francesa, que nos ajudarão a refletir sobre o tema.

\section{DISCURSO, MEMÓRIA E IDEOLOGIA: UM PERCURSO TEÓRICO}

Para los navegantes con ganas de viento, la memoria es un puerto de partida. (GALEANO, 1993, p. 96).

Os caminhos que nos propusemos a percorrer, neste artigo, levamnos a estabelecer relações entre os estudos do discurso e da biblioteca escolar, instalando a dúvida, sacudindo a poeira do que parece estável e claro, apresentando diferentes formas de conceber essa instituição, em documentos oficiais dispostos na Internet, observando tanto quanto possível os efeitos de sentido repetidos e deslocados. Consideramos que, na materialidade virtual, as palavras e os sentidos que elas carregam têm exaltado o seu caráter provisório, contraditório e movediço, suscetível ao movimento de ventos que os levem a lugares outros, mas que são sempre 
impulsionados por sopros de memória que atravessam todo dizer. Deste modo, a Análise do Discurso nos incita a considerar o interdiscurso (PÊCHEUX, 1997), que se refere às regiões do já-lá, da memória, que ora retornam do mesmo modo, ora irrompem como sentido outro e diverso, constituindo a base dos processos de significação, que são o objeto de nosso interesse, nossa curiosidade e nossas indagações.

Para refletirmos acerca dessa questão, iremos nos valer da teia de sentidos sobre a memória que foi urdida especialmente por Michel Pêcheux, seu exímio artesão, para o qual ela é a condição de todo dizer, suportando o funcionamento da linguagem. Nessa perspectiva, não podemos compreender a memória como sendo a lembrança de algo que passou, tampouco como memória institucionalizada nos arquivos, mas como a "voz sem nome" de que fala Foucault (2005), aquela que transpassa os sujeitos no momento da enunciação. Recorrendo a Tfouni e Pantoni (2005, p. 2), temos que, ao sinalizarmos a presença de um já-lá em cada processo de significação, estamos nos referindo ao permanente retorno de sentidos "que foram se construindo historicamente a partir da constelação das relações de poder, que podem ser assumidos ou não pelo sujeito, a depender das posições discursivas que este poderá ou não ocupar em função do funcionamento da ideologia"; por conseguinte, temos que são as imbricações entre sujeito, ideologia e memória que determinam a produção de sentidos, sustentada por uma exterioridade que lhe é constitutiva, ou seja, pelas condições sócio-históricas de produção do discurso.

Investigando mais a fundo a questão da memória discursiva, recuperamos as palavras de Pêcheux (1999, p. 52), para o qual ela seria aquilo que "face a um texto que surge como acontecimento a ler, vem restabelecer os 'implícitos' (quer dizer, mais tecnicamente, os préconstruídos, elementos citados e relatados, discursos-transversos, etc.) de que sua leitura necessita". Deparamo-nos, aqui, com uma questão muito cara ao nosso trabalho, que diz respeito à impossibilidade de negarmos a existência de um já-dito, de um "sempre-já-aí" que estabelece a significação; estamos falando do pré-construído, conceito elaborado por Paul Henry, que se refere a "aquilo que todo mundo sabe" e "que remete a uma construção anterior, exterior" (PÊCHEUX, 1997, p. 99). 
Podemos considerar ainda que o pré-construído, ao lado da articulação (referente ao "como dissemos", "como todo mundo sabe" e "como todo mundo pode ver"), é um elemento do interdiscurso, ou seja, do conjunto de todos os dizeres já falados e filiados a uma formação discursiva ${ }^{1}$, que fornece aos sujeitos a sua "realidade", enquanto um sistema de evidências que faz parecer natural que ele enuncie de uma determinada maneira, silenciando outras. Essa naturalização de sentidos se dá quando um indivíduo é interpelado em sujeito pela ideologia e é levado a acreditar, de forma inconsciente, por meio dos esquecimentos de números 1 e 2, que ele é a origem dos sentidos e que a maneira como ele enuncia, selecionando determinadas regiões de sentidos em detrimento de outras, é a única possível. (PÊCHEUX, 1997).

A partir disso, podemos concluir que não se pode dizer tudo, sendo necessário que se apague, para o sujeito, o funcionamento da memória, pois, se assim não o fosse, ficaríamos impassíveis, petrificados diante do reconhecimento dos estrangeiros postos em discurso por nós, da constatação de que tudo já foi dito. Nas palavras de Borges (2001, p. 100), isso significa dizer que "a certeza de que tudo está escrito nos anula ou nos fantasmagoriza", ou seja, tal constatação nos privaria da própria condição de sermos sujeitos, atravessados pelo esquecimento e a memória para podermos enunciar.

As considerações apresentadas até aqui nos fazem duvidar da crença na regularidade, em um mundo lógico, reduzido e estabilizado, no qual "a língua figura como um conjunto homogêneo, cujos elementos estabelecem relações previsíveis e ordenadas" (ORLANDI, 2003a, p. 205), não se considerando, portanto, a deriva como constitutiva do discurso, o que vai de encontro ao que postulou Pêcheux (2002, p. 53):

Todo enunciado é intrinsecamente suscetível de tornar-se outro, diferente de si mesmo, se deslocar discursivamente de seu sentido

${ }^{1} \mathrm{O}$ conceito de formação discursiva foi elaborado por Michel Foucault e repensado por Pêcheux (1997, p.160), como sendo "aquilo que, numa formação ideológica dada, isto é, a partir de uma posição dada numa conjuntura dada, determinada pelo estado da luta de classes, determina o que pode e deve ser dito [...] Isso equivale a dizer que as palavras, proposições, etc., recebem seu sentido da formação discursiva na qual são produzidas." 
para derivar para um outro (a não ser que a proibição da interpretação própria ao logicamente estável se exerça sobre ele explicitamente). Todo enunciado, toda sequência de enunciados é, pois, linguisticamente descritível como uma série (léxicosintaticamente determinada) de pontos de deriva possíveis, oferecendo lugar a interpretação. É nesse espaço que pretende trabalhar a análise de discurso.

Deste modo, abrem-se brechas para que os sentidos se movam, sem parada, visto que não estão completamente definidos, sendo atravessados pela falta. A partir do que foi exposto, podemos situar o sentido em um lugar provisório, que desestabiliza uma concepção estática de língua, rompida pelas múltiplas possibilidades de significação dadas pelos movimentos de um sujeito cujo dizer é atravessado por outros. Ao enveredarmos por essas questões, deparamo-nos com o conceito de heterogeneidade, que foi desenvolvido, pela linguista francesa Jacqueline Authier-Revuz, a partir da noção de polifonia, formulada pelo teórico Mikhail Bakhtin. Segundo a autora, "sob nossas palavras, 'outras palavras' sempre são ditas [...] atrás da linearidade 'da emissão por una única voz', se faz ouvir uma 'polifonia' [...] todo discurso parece se alinhar sobre várias pautas de uma partitura.” (AUTHIER-REVUZ, 2004, p. 140-141). É ainda a autora que nos propõe que esse atravessamento de vozes no discurso do sujeito pode ocorrer de dois modos, a saber, heterogeneidade constitutiva que se refere ao constante retorno do interdiscurso, do Outro ${ }^{2}$ heterogeneidade mostrada (marcada ou não), que corresponde às "formas linguísticas de representação de diferentes modos de negociação do sujeito falante com a heterogeneidade constitutiva do seu discurso" (AUTHIERREVUZ, 1990, p. 26), remetendo-nos explicitamente à presença do outro que atravessa constitutivamente o um e nos lembra de que os sentidos não estão prontos. Isso pode ser observado, de forma visivelmente marcada,

\footnotetext{
2 Apontamos usos distintos para os termos "outro" e "Outro": o primeiro refere-se à "presença de um outro sujeito enunciador exterior trazido para dentro do discurso, identificável, através das formas mostradas de heterogeneidade. O "Outro" se refere ao interdiscurso funcionando como pré-construído" (MITTMANN, 1999, p. 229), que, segundo Authier-Revuz (2004, p. 69), é "uma condição (constitutiva, para que se fale) do discurso de um sujeito falante que não é fonte-primária desse discurso."
} 
através do uso de citações, aspas, itálico, discurso direto, etc. Como exemplo de heterogeneidade mostrada e não marcada, podemos citar a ironia, a imitação, o discurso indireto livre, metáfora, etc.

É importante apontarmos ainda que, para produzir seu discurso, o sujeito, através das formações imaginárias e suas projeções, pode se desprender de um lugar empírico para ocupar uma ou mais posições no discurso, a partir das quais ele enuncia, produzindo imagens de si e dos objetos discursivos, em meio a um jogo que regula a troca de palavras. Por meio desses jogos imaginários, é possível, por exemplo, que um bibliotecário enuncie a partir do lugar de organizador de acervos, inspetor, educador, aluno, pesquisador, representante de órgão de classe, mediador de leituras, dentre muitos outros possíveis, produzindo diferentes sentidos sobre a biblioteca escolar; assim sendo, no exemplo citado, o que funciona no discurso não é o bibliotecário enquanto indivíduo, mas enquanto uma posição discursiva, produzida pelas formações imaginárias. Segundo Orlandi (2003b), tal jogo imaginário pode ficar ainda mais complexo se incluir a antecipação, pela qual o sujeito tenta antever os sentidos que supostamente seus interlocutores esperam ou gostariam de ouvir. A autora acrescenta que tais jogos imaginários são sustentados por relações de poder, que regulam a produção de sentidos, a partir de um confronto entre o político e o simbólico, no qual intervém a memória e ideologia.

Por fim, nos documentos oficiais que analisamos em pesquisas anteriores (FERRAREZI, 2007, FERRAREZI; ROMÃO, 2008), nós pudemos observar um forte caráter parafrástico dos sentidos de biblioteca escolar, pelo qual há uma volta constante aos mesmos espaços de dizer. Dando continuidade a essas investigações, flagramos, no corpus de análise deste trabalho, alguns movimentos de retorno desses mesmos sentidos, materializados agora em três documentos dos Conselhos de Biblioteconomia disponibilizados na Internet, a saber, o folheto de uma exposição sobre biblioteca escolar realizada em Brasília (ANEXO 1), o Manifesto em Defesa da Biblioteca Escolar, elaborado pelo CFB e os CRB's (ANEXO 2), e a Carta de Brasília do Conselho Federal e dos Conselhos Regionais de Biblioteconomia em defesa da biblioteca escolar (ANEXO 3), que serão analisados a seguir. 


\section{UM PERCURSO DE ANÁLISE: A BIBLIOTECA ESCOLAR NO DISCURSO DA BIBLIOTECONOMIA}

Repetir, repetir - até ficar diferente. (BARROS, 1998, p. 11).

Não faremos aqui uma análise de gênero textual - o que é bastante importante e será desenvolvido em outro estudo -, pois o que nos interessa é interpretar o funcionamento discursivo tal como Pêcheux nos ensinou. Iniciaremos nossas análises trazendo algumas considerações acerca de um cartaz de divulgação de uma exposição sobre a biblioteca escolar (BRASIL, 2009a), que foi realizada entre os dias 17 e 26 de novembro de 2009. Nele, observamos que os sentidos sobre essa instituição desfilam na forma de tópicos onde o sujeito antecipa, tenta antever o que supostamente os sujeitos-leitores aos quais se dirige (por meio de marcas linguísticas como "liberte" e "você") gostariam ou precisariam saber sobre o evento que está sendo promovido, discursivizado. Essa maneira de estruturar o discurso, topicalizando-o, indicia uma tentativa ilusória de condensação dos sentidos (tão cara ao discurso publicitário) sobre o objeto discursivo, na qual o sujeito se esquece (lembrando que esse esquecimento é ideológico) de que há sempre algo que escapa e falha na linguagem, não sendo possível o controle dos sentidos. Assim sendo, o que temos é a atualização de alguns discursos, que representariam o que, pelo jogo das formações imaginárias, foi considerado como o mais importante, digno de ser divulgado, instalando uma maneira de enunciar sobre a biblioteca, que é vista como a única possível.

Investigando a construção desse saber discursivo sobre a biblioteca escolar, pudemos flagrar, nos três documentos analisados aqui, o atravessamento de várias vozes manifestas - no discurso dos órgãos de classe - pela heterogeneidade mostrada e (não-) marcada, que fazem retornar sentidos presentes em documentos oficiais de reconhecidos órgãos internacionais (como a Organização dos Estados Americanos - OEA, International Federation of Library Associations and Institutions - IFLA e United Nations Educational, Scientific and Cultural Organization UNESCO) e, também, órgãos federais brasileiros, como o Ministério da Educação. Inferimos que tais documentos, pelo prestígio que lhes é 
atribuído, conferem um efeito de legitimidade e veracidade àqueles que, assim como os analisados neste artigo, os retomam, efeito este que é reforçado pelo uso de citações e cifras apresentadas como claras e irrefutáveis.

Pela maneira como se faz a costura entre a memória, a ideologia e o discurso, no tecido das relações sociais, vemos serem naturalizados os sentidos que atribuem à biblioteca características consideradas ideais, discursivizando-a a partir de sua importância, fazendo ressoar, nas redes da Internet, a primazia desse "mundo de saber", no qual "tudo começa" (BRASIL, 2009a, p. 1). Notamos, assim, um funcionamento discursivo pelo qual a biblioteca escolar tem seus horizontes alargados, suas funções dinamizadas e os objetivos diferenciados, indiciando o esforço de inseri-la - pelos jogos de formações imaginárias - em outra posição discursiva, ainda que esta não corresponda ao seu lugar social.

Notamos tal modo de constituição de sentidos nos documentos dos conselhos de Biblioteconomia, nos quais a repetição de alguns verbos materializa efeitos de movimento e dinamicidade, na medida em que discursivizam as funções a serem desempenhadas pelas bibliotecas escolares. Isso pode ser observado nas seguintes marcas linguísticas: "promove", "influenciar", “incentivar", "viabilizar" "estimula", "organizar", "trabalhar", "atua", "investirem" e "interagem", que sinalizam uma tentativa de romper com discursos que historicamente atribuíram às bibliotecas a exclusiva e estática função de armazenar e conservar acervos. A presença de sentidos mais plurais pode indiciar um desejo de mudança nas práticas realizadas nas bibliotecas escolares, pelo qual se buscaria tecer uma relação com o sujeito-leitor, cativá-lo, atraí-lo e não apenas esperar que ele adentre o portão da biblioteca e percorra as suas estantes.

Inseridos nessa região de sentidos, que introduz a biblioteca em uma posição de maior prestígio, visibilidade e atuação, na escola e na sociedade (evocando, como já sinalizamos, um já-dito presente especialmente em documentos oficiais internacionais e em documentos científicos que normatizam o que/como deve ser uma biblioteca escolar ideal), estão os discursos que a associam a um "centro de aprendizagem" com "função pedagógica” (BRASIL, 2009b, P. 4), pela qual ela deveria atuar em prol da aprendizagem permanente, o estímulo à criatividade, comunicação, cultura, 
recreação e a formação docente; oferecendo o acesso a diversos recursos que devem estimular a polissemia; assumindo um papel político e estendendo suas ações para a comunidade escolar e externa, a fim de derrubar os muros que, há séculos, separam-na da grande maioria da população, conforme podemos observar nos recortes a seguir:

[...] elemento que forma o indivíduo para aprendizagem permanente; estimula a criatividade, a comunicação, facilita a recreação, apoia os docentes em sua capacitação e lhes oferece informação necessária para tomada de decisão na aula. (BRASIL, 2009a, p. 1, grifos nossos).

A biblioteca escolar não somente lida com as demandas do aluno, mas, sobretudo, atua no contexto do projeto político-pedagógico da escola, através do trabalho conjunto com o professor e a gestão escolar. (BRASIL, 2009b, p. 4, grifos nossos).

Espaço de aquisição e disseminação de cultura e informação (BRASIL, 2009b, p. 5, grifos nossos).

[...] ambientes de busca e aprimoramento de conhecimentos. (BRASIL, 2009b, p. 4, grifos nossos).

Favorecer o acesso a recursos locais, regionais, nacionais e globais e a oportunidade para que os estudantes exponham diferentes ideias, opiniões e experiências. (BRASIL, 2009a, p. 2, grifos nossos).

Entre as ações consideradas como as mais importantes para serem desempenhadas nas bibliotecas, destaca-se a promoção de atividades e serviços, cujo enfoque é dado especialmente à leitura e à pesquisa, constituindo uma maneira de falar sobre a biblioteca, na qual estaria implícita a necessidade de um movimento de leitores para que ela se signifique:

Promover a leitura, recursos e serviços da biblioteca a toda a comunidade escolar e à comunidade externa (BRASIL, 2009a, p. 2, grifos nossos). 
[...] permite o fomento da leitura [...] uma ação em prol da leitura e do incentivo à criação do gosto e hábito de ler (BRASIL, 2009a, p. 1, grifos nossos).

Espaço para o desenvolvimento da pesquisa escolar e do trabalho intelectual [...] (BRASIL, 2009a, p. 1, grifos nossos).

Considerando que uma das atividades a ser desenvolvida pela biblioteca escolar é o incentivo à leitura [...]. (BRASIL, 2009b, P. 4, grifos nossos).

[...] importância da biblioteca na prática da leitura e escrita [...] um espaço apto a influenciar e incentivar a prática da leitura e escrita [..] espaço de excelência na aquisição de leitura e escrita (CARTA..., 2007, P. 1, grifos nossos).

Frisamos que, apesar de fazerem circular sentidos que sustentam um dizer sobre a importância da realização de atividades de natureza literária e cultural, nenhum dos três documentos que analisamos nesse artigo aponta, de maneira efetiva, como a biblioteca escolar pode alcançar as metas propostas, exercer tais atividades às quais é chamada. Tal silenciamento de sentidos, que procurem ir além da repetição de discursos que ponham em circulação sentidos sobre o "que" e não o "como" fazer, constitui um funcionamento discursivo que observamos ao longo dos últimos anos em que nos dedicamos a investigar o discurso sobre a biblioteca escolar, lembrando-nos de que as palavras transpiram sentidos que já foram falados em outros lugares, de que diversas vozes atravessam as palavras que mobilizamos para construir o nosso discurso.

Observamos que, na heterogênea teia digital, os sentidos apresentados até aqui se amarram a outros, que vão de encontro a eles, instalando a contradição, pela qual se discursiviza a biblioteca escolar como uma simples coadjuvante, mero "instrumento", "suporte", para realizar a "missão da escola". Pelo jogo das formações imaginárias, a biblioteca escolar é enunciada a partir do seu caráter funcional, que conferiria ao sujeito-aluno a possibilidade de "desempenhar seus papéis sociais", ir ao encontro do que se espera dele, ou seja, constituir-se como "cidadão" com "consciência cultural e social", em uma sociedade pretensamente democrática, atribuindo-lhe, assim, direitos, como liberdade e acesso às informações, na medida em que normatizam qual seu dever perante a 
sociedade. Para tanto, retornam, através da heterogeneidade mostrada não marcada, sentidos circulantes nos documentos internacionais que atestam os direitos dos cidadãos, por meio dos quais a educação é vista como direito de todos (exaltação dos valores democráticos), condição para a cidadania, civilização e cultura.

Vejamos alguns recortes em que tais sentidos aparecem:

Espaço para o desenvolvimento da pesquisa escolar e do trabalho intelectual que proporcionarão ao educando meios para desempenhar seus papéis sociais. [...] Ação cultural com vista a favorecer o entendimento da identidade do cidadão no espaço onde vive. (BRASIL, 2009a, p. 1, grifos nossos).

Organizar atividades que estimulem a sensibilidade e a consciência cultural e social [...] Trabalhar com estudantes, professores, administradores e pais para realizar a missão da escola. [...] Proclamar a ideia de que a liberdade de expressão e o acesso à informação são essenciais à efetiva e responsável cidadania e participação na democracia. (BRASIL 2009a, p. 2, grifos nossos).

[...] proporcionarão ao educando meios para melhor desempenhar seus papéis sociais $[\ldots]$ favorecer o entendimento da identidade do cidadão. (BRASIL, 2009b, P. 4, grifos nossos).

A qualidade da educação acha-se intimamente ligada à oferta, pela escola, de meios, instrumentos, equipamentos e suporte para que o educando integre-se à cultura, assimile, processe e produza enquanto sujeito do processo civilizatório, sujeito da construção da cidadania. Este (sic) o sentido das disposições do art.205 da carta magna. (CARTA..., 2007, P. 1, grifos nossos).

Através do que foi exposto, inferimos que, ao enunciarem a partir desta perspectiva sobre as bibliotecas escolares - que restringe tanto as funções atribuídas às mesmas quanto os movimentos dos sujeitos-leitores, aos quais é imputado (ilusoriamente) um caráter homogêneo, como se fosse possível que todo sujeito tecesse sentidos da mesma maneira, possuindo as exatas e tão requeridas habilidades, "competências" em informação, leitura e escrita (BRASIL, 2009b; CARTA..., 2007) -, temos o pressuposto de que apenas os saberes autorizados no âmbito escolar são legítimos, adequados, 
úteis, e que o aluno precisa sujeitar-se a eles para ser um "cidadão civilizado", isto é, para que não seja como aqueles que, por não terem recebido uma educação formal, são como "bárbaros", à margem da sociedade, da cultura e do progresso.

Como todo dizer cala uma série de outros que poderiam estar em seu lugar, observamos o silenciamento de sentidos que, em outros contextos, poderiam discursivizar a biblioteca escolar de uma maneira diferente, fazendo falar, por exemplo, o prazer de estar na biblioteca, participar de inúmeras atividades dinamizadoras dos acervos e abrir-se a outras significações, além dos fechados currículos escolares:

A inclusão do sujeito-escolar no processo educacional, via biblioteca, é considerada a maneira pela qual ele pode se constituir um 'cidadão responsável' [...] um 'membro útil da sociedade', o que, para nós, é uma pista linguística importante pois reforça o efeito utilitário e instrumental atribuído à própria biblioteca escolar, definida como o lugar que o cidadão vai frequentar para se tornar útil e necessariamente integrado ao papel que lhe é reclamado no âmbito social da produção e produtividade. Não se discursiviza o prazer nem o deleite que poderiam advir do contato com os livros e outros materiais, mas se normatiza, tão somente, a serventia de adentrar esse espaço. (FERRAREZI; ROMÃO, 2008, p. 330-331).

A partir disso, as funções da biblioteca escolar estariam limitadas ao apoio (e não ao centro) à aprendizagem, priorizando o currículo escolar, a promoção de livros (e não de outros materiais também) e o acesso universal à informação, como se ele fosse o fim, e não o início de práticas que coloquem o acervo em movimento, de forma mais crítica e criativa, que gerem realmente a oportunidade de exposição de "diferentes ideias, opiniões e experiências" (BRASIL, 2009a, p. 2). Limita-se, assim, o escopo de ação da biblioteca escolar, desconsiderando as várias outras funções e atividades que poderiam ser nela desempenhadas, indo de encontro aos sentidos de que a biblioteca não pode assumir apenas uma função didáticopedagógica, devendo, segundo Perrotti (2006), não apenas apoiar o programa do professor, mas ir além; marcamos que tais sentidos evocam uma maneira mais ampla e polissêmica de discursivizar a biblioteca, que está ausente nos recortes a seguir: 
[...] instrumento de desenvolvimento do currículo. (BRASIL, 2009a, p. 1, grifos nossos).

Apoiar a todos os estudantes na aprendizagem e prática de habilidades para a avaliação e uso da informação. (BRASIL 2009a, p. 2, grifos nossos).

[...] promove serviços de apoio à aprendizagem e livros aos membros da comunidade escolar. (BRASIL, 2009b, p. 4, CARTA..., 2007, p. 1, grifos nossos).

Entremeados a esses sentidos, a nosso ver restritos, estão aqueles presentes na "Carta de Brasília em Defesa da Biblioteca Escolar", em cujo título antevemos o funcionamento discursivo que nela se encontra, pelo qual, ao serem apresentadas as dificuldades e os problemas enfrentados pela biblioteca escolar inserida em um preocupante contexto educacional, ela é revestida de um caráter frágil, ocupando a posição daquele que deve ser discutido, protegido e defendido (assim como se apresenta também no Manifesto em Defesa da Biblioteca Escolar), por um sujeito legitimado, autorizado a enunciar, manifestar-se e agir sobre ela. Pela deriva que constitui o discurso, garante-se a possibilidade de que a biblioteca possa ocupar, ao mesmo tempo, uma posição diferente, construindo outros sentidos, pelos quais ela é chamada a exercer um papel mais ativo, que a distancie da inércia que lhe é historicamente atribuída, conclamando-a a intervir politicamente, fazendo com que "esta triste realidade" possa ser transformada.

Deste modo, observamos os sentidos que atribuem à biblioteca a possibilidade de ser uma solução, uma saída para os preocupantes problemas educacionais enfrentados pela sociedade brasileira, os quais são também alvo de denúncia e críticas, parafraseadas nos documentos que analisamos. Temos, assim, que, ao serem satisfeitas as condições (consideradas ideais pelos órgãos de classe dos bibliotecários) de atuação, que incluem profissionais habilitados e acervos qualificados, as bibliotecas poderiam superar as dificuldades encontradas, como podemos observar nos recortes a seguir: 
[...] preocupação com o momento pelo qual passa a educação no Brasil, com baixos índices de aprendizagem dos alunos, mensurados tanto pelo Sistema de Avaliação da Educação Básica (SAEB), quanto pelo Programa Internacional de Avaliação de Alunos (PISA), demonstrando que os estudantes brasileiros não possuem competência em leitura e escrita. (BRASIL, 2009b, p. 4)

[...] importância da biblioteca na prática da leitura e escrita, um dos maiores problemas da educação atualmente [...]. (BRASIL, 2009b, p. 4).

Acompanhamos com preocupação o momento por que passa a educação no Brasil, com baixos índices de aprendizagem dos alunos, demonstrando que eles não possuem competência em leitura e escrita. Diante desse fato, acreditamos que se as instituições de ensino investirem na criação de espaços de bibliotecas bem equipadas, com acervos que atendam ao projeto político pedagógico das escolas e administradas por profissionais bibliotecários, está [sic] triste realidade poderá sofrer significativa transformação. (CARTA..., 2007, p. 1, grifos nossos).

[...] acredita-se que se as instituições de ensino investirem na criação de espaços de bibliotecas bem equipadas, com acervos que atendam ao projeto político pedagógico das escolas e administradas por profissionais bibliotecários, esta triste realidade poderá sofrer significativa transformação. (BRASIL, 2009b, p. 4, grifos nossos).

Sendo assim, a biblioteca escolar é discursivizada a partir de um lugar de importância, e a Internet funciona como um (ciber)espaço discursivo em que é possível materializar efeitos de luta e reivindicação que gravitem em torno da biblioteca escolar, instalando um litígio entre diferentes sentidos. Pela contradição que é constitutiva do discurso, é possível que os sentidos que colocam em discurso uma biblioteca ideal circulem lado a lado daqueles que os desconstroem, estabelecendo relações conflituosas, que chamam a atenção para a possibilidade (presidida pelas formações imaginárias) de a biblioteca ocupar uma posição discursiva diferente do lugar social a partir do qual se enuncia. Esse movimento foi flagrado, também, no Manifesto sobre a Biblioteca Escolar que, como o próprio nome ("manifesto") sugere, evoca sentidos circulantes no campo 
político que, por sua vez, serão deslocados e materializados na rede eletrônica, para enunciar sobre a biblioteca escolar. Consideramos que a Internet pode ser entendida como um espaço heterogêneo, no qual também é possível instalar a dúvida acerca dos sentidos atribuídos a uma biblioteca escolar ideal, manifestar-se criticamente a respeito dela. Observa-se, assim, um embate entre diversas formas de discursivizar a biblioteca escolar, diferentes formações discursivas que se interpenetram, graças à porosidade de suas fronteiras. E isso também tem relação com a heterogeneidade do nosso corpus, que inclui a seleção de um cartaz, de um manifesto e de uma carta, justamente para observá-los, não como gêneros textuais ou discursivos com características diferentes, mas como discurso cuja regularidade pode ser inscrever em diferentes estruturas de textos.

A partir do que foi exposto, consideramos que a rede eletrônica é um espaço político de disputas pelo dizer, onde é possível flagrar os movimentos de significação constituídos pelos sujeitos-bibliotecários, promovendo a circulação dos sentidos de denúncia acerca das condições precárias das bibliotecas, pelos quais se instaura a contradição entre o ideal de acesso universal a uma biblioteca e o panorama desanimador brasileiro, marcado pela inexistência e mau funcionamento das bibliotecas escolares, especialmente da rede pública de ensino:

Ainda, é oportuno destacar que, na maioria dos casos, o horário de atendimento não é regular nem suficiente para atender aos estudantes, sendo que os raros frequentadores pouco usam ou têm consciência de suas potencialidades em termos de serviços. (MANIFESTO..., 2009, p. 4, grifos nossos).

[...] as escolas não possuem bibliotecas e muito menos bibliotecários [...]. (BRASIL, 2009b, p. 4, grifos nossos).

[...] apresenta-se carente de um serviço cidadão. (CARTA..., 2007, p. 2, grifos nossos).

Abre-se, também, espaço para duvidar dos discursos legitimados que exaltam as ações governamentais distributivistas, supostamente em prol da biblioteca escolar, para questionar a ordem vigente, através da indagação sobre a priorização da simples existência de um acervo na escola, em 
detrimento de sua dinamização no âmbito da biblioteca, como podemos observar nos próximos recortes:

No que pese ser esta a única iniciativa desenvolvida no âmbito da federação para as bibliotecas escolares, é tácito afirmar que tal Programa não atende as expectativas do contexto no qual se inserem as discussões apresentadas, pois, se as escolas não possuem bibliotecas e muito menos bibliotecários, como estão sendo dinamizados esses acervos? (BRASIL, 2009b, p. 4, grifos nossos).

Ressalte-se que biblioteca escolar, embora se constitua em um espaço de aquisição e disseminação de cultura e informação, apresenta-se carente das condições adequadas para ofertar um serviço cidadão, no sentido de que está impedida de viabilizar um processo de democratização da informação com amplo acesso aos meios de cultura, uma vez que a sua existência está condicionada única e exclusivamente à presença de acervo, e não à oferta de serviços capazes de promover o acesso aos saberes registrados nos artefatos culturais que a biblioteca escolar deve disponibilizar. (BRASIL, 2009b, p. 4, grifos nossos).

Inferimos que, apesar do reconhecimento de que o acesso ao acervo por si só não é suficiente, de que é preciso dinamizá-lo, não se avança em questões que apontem como isso seria possível, apagando-se os sentidos acerca de uma relação mais polissêmica com a linguagem, de uma postura mais plural da biblioteca escolar, que superem o ranço burocrático ainda presente nas bibliotecas brasileiras. Isso pode ser observado no embate entre os sentidos de crítica a práticas consideradas restritas e os que preconizam apenas a existência de bibliotecas, bibliotecários e acervos tecnicamente processados como formas de superar as dificuldades:

O gasto de numerário público, como já destacado, em simples aquisição e distribuição de acervo, principalmente composto de livros, sem abranger a existência, organização e manutenção de bibliotecas fere o interesse público, já que em última instância, esses recursos são extraídos dos cofres públicos a partir da arrecadação efetuada através do contribuinte, configurando-se em malbaratação do patrimônio cultural. (BRASIL, 2009b, p. 5, grifos nossos). 
[...] acredita-se que se as instituições de ensino investirem na criação de espaços de bibliotecas bem equipadas, com acervos que atendam ao projeto político pedagógico das escolas e administradas por profissionais bibliotecários, esta triste realidade poderá sofrer significativa transformação. (BRASIL, 2009b, p. 4, grifos nossos).

[...] direito do cidadão em ter acesso a um espaço no qual a informação concretiza seu papel social, democratizante, vez que não se pode pretender que o acervo não processado de forma técnica, científica, atenda a essa função que, por ser social é garantia da construção da cidadania. (BRASIL, 2009b, P. 5, grifos nossos).

É exatamente, diga-se de outro modo, a informação que se organiza, processa e se dissemina, após receber o tratamento adequado, que poderá atender ao cidadão em amplo raio de demandas e níveis de compreensão. (BRASIL, 2009b, P. 5, grifos nossos).

É nesse espaço que a informação concretiza seu papel social, democratizante, vez que não se pode pretender que o acervo não processado de forma técnica, cientifica, atenda a essa função que, por ser social é garantia da construção da cidadania. É exatamente, repita-se, a informação que se organiza, processa e se dissemina após receber o tratamento adequado, que poderá atender ao cidadão em amplo raio de demandas na construção da educação cidadã. (CARTA..., 2007, P. 2, grifos nossos).

Consideramos que é importante que a biblioteca conte com recursos que permitam que ela se torne um ambiente agradável e desejável, dotada de acervos organizados e disponíveis, entretanto, ressaltamos que esses recursos devem ser postos em movimento, e não, como sugerem os recortes anteriores, apenas estarem disponíveis para o acesso e utilização em atividades escolares que, geralmente, são desempenhadas de forma repetitiva em grande parte das escolas brasileiras, que sustentam ainda a transmissão e não a construção do conhecimento.

Os discursos que atribuem sentidos de passividade e restrição à biblioteca escolar entremeiam-se a outros que procuram valorizá-la, colocála em movimento, em direção aos sujeitos leitores, através de ações que a desprenderiam do plano teórico e estariam voltadas, principalmente, para a 
sua maior visibilidade, rompendo, assim, com o silenciamento a que muitas vezes é submetida. Dentre essas ações propostas, destacam-se a "elaboração de um manifesto a favor da biblioteca escolar a ser publicado em todos os jornais do país"; "Eleger uma figura pública para apoiar o movimento" e "levantar e expor as boas práticas existentes no país." (BRASIL, 2009b, p. 5), que seriam realizadas pelos órgãos de classe, a partir da implicação do sujeito nesse discurso, que assumiria uma posição de mobilização, de reivindicação do que é considerado como direito básico, legitimado pela lei:

[...] as organizações abaixo-assinadas reivindicam o respeito aos princípios estabelecidos na Constituição Federal (1988), no que tange ao direito do cidadão em ter acesso a um espaço no qual a informação concretiza seu papel social, democratizante [...]. (BRASIL, 2009b, p. 5).

Assim, insere-se o sujeito-bibliotecário em um lugar de poder, de importância, a partir do qual ele deveria assumir um papel de destaque, frente aos desafios impostos às bibliotecas escolares. Observamos que os discursos circulantes nos documentos do CFB e CRBs - organizações sociais imbuídas do poder de falar, supostamente, em nome de todos os bibliotecários, representando claramente as suas opiniões e interesses evocam sentidos de valorização desses profissionais e, também, de denúncia frente à sua ainda inexpressiva presença nas escolas brasileiras. Esses sentidos que, pelo esquecimento número dois (PÊCHEUX, 1997), parecem óbvios, sendo natural que em toda biblioteca haja um bibliotecário, não estiveram presentes, de forma maciça, nos documentos jurídicos brasileiros até a aprovação da Lei $\mathrm{n}^{\mathrm{o}}$ 12244/2010, que visa à universalização das bibliotecas nas instituições de ensino do Brasil, respeitando-se, para tanto, a profissão de bibliotecário (BRASIL, 2010). Tal lei estabelece um prazo de dez anos para sua efetivação e subsequente implementação de mudanças que revertam esse histórico quadro de dificuldades, sustentando a produção de outros sentidos de biblioteca escolar; e não se trata aqui de um documento fundador sobre o tema no país, mas de uma discursividade que renegocia os efeitos de outros 
documentos já aprovados pela Unesco e em vigência, por exemplo. Para reforçar os sentidos de importância do profissional da informação, considerado como aquele que detém o saber necessário para atuar nas bibliotecas, desqualificam-se outros que, por não terem os mesmos conhecimentos que eles, estariam expondo-se aos perigos, a essa imprudência de desempenhar tarefas para as quais não foram preparados, estando fadados ao fracasso:

[...] a grande maioria dos responsáveis técnicos e diretores das escolas não tem noção dos serviços que podem ser oferecidos pelas bibliotecas. (BRASIL, 2009b, 2009, p. 4, grifos nossos).

Os diretores das escolas e os responsáveis técnicos não têm domínio sobre a concepção do funcionamento de uma biblioteca e se arriscam ao apontar a dimensão do espaço físico destinado a leitura como única diferença entre biblioteca e sala de leitura. (BRASIL, 2009b, p. 4, grifos nossos).

A Lei no 4.084, de 30 de junho de 1962, dispõe sobre a profissão de Bibliotecário e regula seu exercício. Em seu Art.6 o determina '[...] que entre as atribuições dos Bacharéis em Biblioteconomia estão a organização, a direção e execução dos serviços técnicos de repartições públicas federais, estaduais, municipais e autárquicas e empresas particulares'. O exercício dessas funções por leigo constitui uma infração à legislação vigente $e$, principalmente, fere o direto constitucional do cidadão de receber a prestação de serviços por profissional especializado e habilitado [...]. (CARTA..., 2007 , p. 2, grifos nossos).

Nessa perspectiva, recorre-se mais uma vez à citação de documentos jurídicos, para conferir um efeito de veracidade e comprovação aos sentidos enunciados, que sustentam uma crítica a tudo aquilo que é considerado inadequado em relação à biblioteca, como, por exemplo, a presença do "leigo", cujo avesso é a inexistência do bibliotecário (inserido em um lugar de poder e saber), a qual é vista, a partir dessa perspectiva, como um desrespeito à lei, uma infração dos direitos do cidadão, atestados em vários documentos jurídicos que são retomados para fazer falar a necessidade e importância das bibliotecas e dos bibliotecários. 


\section{CONSIDERAÇÕES FINAIS}

Ao longo deste estudo, buscamos um exercício de reflexão sobre os efeitos de sentido repetidos e deslocados sobre biblioteca escolar, analisando como eles se inscrevem em documentos diversos. Marcamos os modos de circulação desses efeitos, implicados na oficialidade da voz das instituições e dos governos, e as suas ressonâncias em outras discursividades, quais sejam, a voz dos profissionais da informação e da educação. A Internet funcionou como uma arena onde pudemos escutar e coletar os dados, analisando-os à luz da teoria discursiva; anotamos que a materialidade digital propicia a emergência de sentidos tão plurais quanto movediços, deslocantes e migratórios, o que pode (e deve) desautorizar a regulação que, pela interpelação ideológica, faz parecer evidente que leitura, biblioteca e livros são igualitariamente distribuídos quando da publicação de documentos oficiais.

A partir do que foi exposto até aqui, podemos inferir que a Internet é um espaço discursivo atravessado por relações de força, lutas pelo poder saber e dizer, pelas quais o sujeito pode resistir, fazer ecoar sentidos de denúncia, rompendo os efeitos de silenciamento da biblioteca escolar e do bibliotecário. Deste modo, em meio aos sentidos repetitórios, flagramos a emergência de outros, que se entremeiam a eles, instalando um litígio entre o mesmo e o diferente, lembrando-nos de que todo enunciado pode ser descrito como uma série de "pontos de deriva possíveis" (PÊCHEUX, 2002, p. 53), que oferecem um lugar à interpretação, convocando-nos a duvidar da transparência dos sentidos aparentemente óbvios e estabilizados; convite este que estendemos a você, caro leitor, de modo a instigarmos a adoção de novas práticas nas bibliotecas escolares, suscitadas por um olhar que, em meio à repetição e ao já-estabilizado, possa se abrir ao diferente, tal como propõe Barros (1998), na citação que nos serve de epígrafe e com a qual encerraremos esse texto, sem a pretensão e ilusão de esgotarmos o tema, mas com o desejo de termos provocado novas reflexões, a partir da perspectiva do discurso, que pode contribuir com os estudos sobre a biblioteca escolar. 


\section{REFERÊNCIAS}

AUTHIER-REVUZ, J. Heterogeneidade(s) enunciativa(s). Cadernos de Estudos Linguísticos, n.19, p. 25-42, 1990.

. Heterogeneidade mostrada e heterogeneidade constitutiva: elementos para uma abordagem do outro no discurso. In: . Entre a transparência e a opacidade: um estudo enunciativo do sentido. Porto Alegre: EDPUCRS, 2004. p. 11-80.

BARROS, M. Livro da ignorãças. Rio de Janeiro: Record, 1998.

BORGES, J. L. A biblioteca de Babel. In: . Ficções. 3. ed. São Paulo: Globo, 2001.

BRASIL. CONSELHO FEDERAL DE BIBLIOTECONOMIA. Exposição Biblioteca: Tudo começa aqui. 2009a. Disponível em:

$<$ http://www.cfb.org.br/UserFiles/File/

eventos/cartaz.pdf>. Acesso em: 20 jan. 2013.

. Manifesto em Defesa da Biblioteca. Bob News CRB-8, n.5, p. 4-5, jun. 2009b. Disponível em:

$<$ http://repositorio.cfb.org.br/bitstream/123456789/265/1/BOBNEWS

_Vol1_Numero5_mar2009.pdf >. Acesso em: 20 jan. 2013.

BRASIL. Lei $n^{\circ}$ 12244, de 24 de maio de 2010. Dispõe sobre a universalização das bibliotecas nas instituições de ensino do País. Diário Oficial da União. Brasília, 25 maio 2010. Disponível em: <http://www.jusbrasil.com.br/diarios/5259000/dousecao-1-25-05-2010-pg-3>. Acesso em: 20 jan. 2013.

CARTA de Brasília do Sistema Conselho Federal e Regionais de Biblioteconomia em Defesa da Biblioteca Escolar. 2007. Disponível em:

$<$ http://repositorio.cfb.org.br/

bitstream/123456789/318/1/BIBLIOTECAESCOLAR.pdf $>$. Acesso em: 20 jan. 2013.

FERRAREZI, L. O imaginário sobre a biblioteca escolar: sentidos em discurso. 2007. 106 f. Trabalho de Conclusão de Curso (Graduação em Ciências da Informação e da Documentação) - Faculdade de Filosofia Ciências e Letras de Ribeirão Preto, Universidade de São Paulo, Ribeirão Preto, 2007.

. A biblioteca escolar nas teias do discurso eletrônico. 2010. Dissertação (Mestrado em Ciências) - Universidade de São Paulo, Ribeirão Preto, 2010.

; ROMÃO, L. M. S. O dizer dos documentos oficias: a normatização como efeito de sentidos sobre a biblioteca escolar. $A C B$, Florianópolis, v.13, n.2, p. 323- 
346, jul./dez., 2008. Disponível em:

$<$ http://revista.acbsc.org.br/index.php/racb/article/

viewFile/536/666>. Acesso em: 20 jan. 2013.

FOUCAULT, M. A ordem do discurso. 12. ed. São Paulo: Edições Loyola, 2005.

GALEANO, E. Las palabras andantes. Coyoacán, México: Siglo Veintiuno,1993.

MITTMANN, S. Heterogeneidade e função tradutor. Cadernos de Tradução, Florianópolis, v.1, n.4, p. 221-237, 1999. Disponível em:

$<$ http://www.periodicos.ufsc.br/ index.php/traducao/article/viewFile/5533/6575>. Acesso em: 24 fev. 2010.

ORLANDI, E. P. A leitura e os leitores. 2. ed. Campinas: Pontes, 2003a. 2003b.

. Análise de discurso: princípios \& procedimentos. 5.ed. Campinas: Pontes,

PÊCHEUX, M. Semântica e discurso: uma crítica à afirmação do óbvio. Tradução de Eni Pulcinelli Orlandi et al. 3. ed. Campinas, SP: Editora da UNICAMP, 1997.

. Papel da memória. In: ACHARD, p. et al. Papel da memória. Tradução de José Horta Nunes. Campinas: Pontes, 1999. p. 49-57.

. O discurso: estrutura ou acontecimento. Tradução de Eni Puccinelli

Orlandi. 3.ed. Campinas: Pontes, 2002.

PERROTTI, E. Biblioteca não é depósito de livros. [Entrevista concedida a Márcio Ferrari]. Nova Escola, ed. 193, jun. 2006. Disponível em:

$<$ http://revistaescola.abril.com.br/lingua-portuguesa/pratica-pedagogica/bibliotecanao-deposito-livros-423601.shtml>. Acesso em: 9 dez. 2009.

SARAMAGO, J. O Evangelho segundo Jesus Cristo. São Paulo: Cia das Letras, 2003.

TFOUNI, L. V.; PANTONI, R.V. Sobre a ideologia e o efeito de evidência na teoria da Análise do Discurso francesa. Achegas, n. 25, set./out., 2005. Disponível em: $<$ http://www.achegas.net/numero/vinteecinco/leda_e_rosa_25.htm $>$. Acesso em: 10 mar. 2010. 


\section{Exposiç̃̃o}

\section{Biblioteca Escolar: Tudo começa aqui}

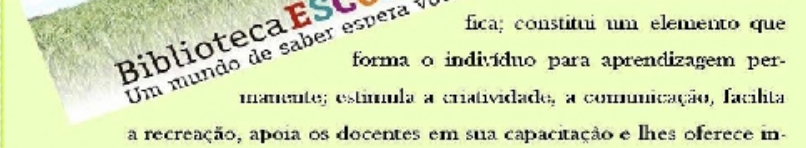

a recreaçăo, apoia os docentes em sua capacitaçào e lhes oferece in.

Fonmaçáo necessáuia para comada de decisäo na anda. (OEA, 1985, p.21-22)

A bibliusaca esxolar ta mu
instrumento de desenvolvi-

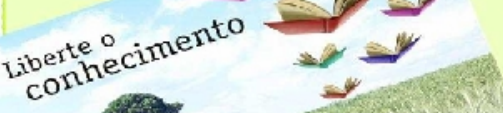

mento do currículo e

permita: a torments da

leinura e da formaçio

de una atitude cienti-

fica; constitui um elemento que

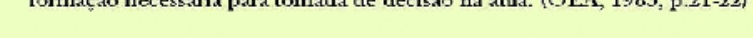

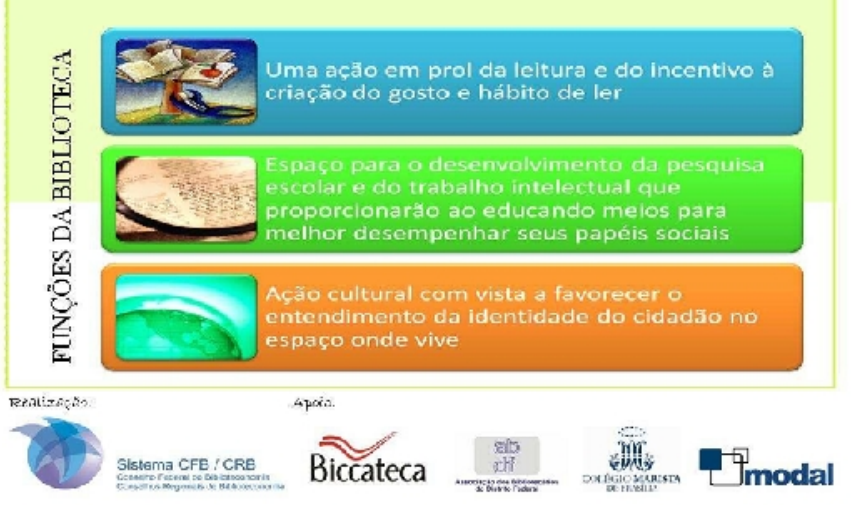




\section{Manifesto em Defesa da Biblioteca Escolar}

No contexto do projeto de ensino-aprendizagem, a blbilateca scolar apresenta-se comb um certro de aprendizagern cuja funçăo pedagógica está ralacio nada a: a) uma açä́o em prol da Icitura, do incentivo à criaģo do goste de ler; b) a pesquiso esco lare as trabalto intelectual aue proporcionarễo as educardc melcs para melhor desemperhar stus papéis sociais; e c) a açu cullural cam vishas a fevervecer entendimenth da idertidade dc cidacão no espaçc onde vive. $\Delta$ blblloteca escolar nấo somente lida com us demandas do aluno, mas, sobretuds, atua no contexto do projeto politico-pedagógice da escola, através do trabalhc conjunto com o professor e a yes Lüo cscclar.

Segundo o Manifesto da UI NFSCO, a bihlioteca escolar é espaço que " [...] promove servltos de apoio à aprendisaben livros aus merrbrus da comuri tade escolar, ofererendo-lhes a possibllidade de se tornarem pensadores criticos e efetivos usuários da infurmaçá, em to dos os formatos e meics", ol seja, competentes fm informaप्रें?.

As enlidades a prssons fisicas que assiram este Manifesto $=x$ pỏem sua preocupaçă com c momento pelo qual passa a educaçue no Brasil, com baixos indi tes de aprendizager dos altnos, mensurados tanto pelo Sistema de Avallaçäo da Educaçấc Eúsica (SAEB), quan lo pelo Pro grarra Internacional de Avalia ă de Alunos (PISA), demonstrancs que os estudantes brasllelros nẫo possuem competencla enl leitura e escritu. Diante des te fato, acredita-se que se as instituiçc̃es de ensiro investirem na crlação de espaços de blbllo lecas bem equipades, com acervos que atendam ao projets político pedagógicn das escolas e administracas por profissionais bibliotecúrios, esta triste realidide podera solrer significalive transformacลัo.

Alguns documentos elaborados pelo $\mathrm{K} /$ iristerio da Educaçấc apontam para a Impcrtancla da biblioteca na prática da lcitura c scrilo, un dos muieres proble mas da educação atualmente, dentre estes citarr-se os Parâmetros Curriculares Nacionals (PCN's), que, ne módulo de Línyua Purtugueso cile a biblioteca mmo um espaco apto a influerciar e incentivar a prática da leitura e escrita.

o Frograma Nacional Bibliete 1 cid Facoles (PNBE) distribu acervos para bihliotecas escola res. No que pese ser esta a única iniclativa deservolvida nc imbile de federaçúo para d: hiblioteras escolares ${ }^{2}$, ̀́ tácito afirmar que tal Proçrama não atende as expectativas do cortexto ro qual se Inserem as discussües apresentudus, pois, sc as escolas năo possuem bihlintecas a muitn menns bihliotecárlos, como estấo senco diramlzados usses accruos?

Dc fato, os diugnústicos cxis tentes no Pais acerca das condigies das blbliotecas escolares, bem como as declsōes emanadas do Tribunal de conlos de Uniăo (TCU) em seLs Acórdăos n. 504/2004 e n०1287/2005, apontam que a grande maioria dos respunséveis lécricos a diretores das excolas não tem nocäo dos serviços cue podem ser oferecidos pelas blbliotecas, c que impedc a criaģuo de muilas oportunidades e que essas bibliotecas atuen como ambientes de busca e aprimoramento de conthecimentus. Os diretores das eccolas + os responsádveis lécrims nắc têm dorrinio sobre a corcepção do furclonamento de uma blblloteca e sc arriscam ac uportar a dirnensũo do espace f́sico destinado a leitura como única difererça entre biblicteca e sala de leltura: a blblioteca seria aclols com moior cespoco fisico, a despeito da corstituicăo do acervn, servicos oferecidos $F$ nivel de tratamento e orgarizaGio des obras. Ainda, oportuno veslacar que, na meioria dos casos, o horário de atendimento nốo é regular nem suficlente para atender acs estudantes, serco que os raros freqüentadores polco lsam ou tem consc êricia de suas polencialidades en termos de senjiçns. Os dados do Censo Escolar 2004 destacam que $51,7 \%$ dos alunos do ensine búsico e profissional tis póem de bibliotecas csculares, năo permitem inferir que estes discentes de fato as usem, ou, pelo menos, reconheçam a exisléncia destes espaços para mo diar geu [rocesso to ensint aprendizagem.

Considerando cle ura das atividades a ser deservolvida pela biblicteca escolar tivo à leitura, O Instituto PrthLeitura (TPL) efetuou, no primeiro semestre de 2008, a segurda edlçäo da pesquisa Retratos da Leilura no Brasil, que se constitui ro principal estuds sobre o compoitamento do leitor no PaIs, ra expectativa de contribuir para a aveliacaro das impactos das políticas públicas que possi bilitem o ackssn ao livro ₹ à leitura, visando identificar as que efetivamente trouxeram resultados no incertivs ao gosto de ler.

Dentre suas conclusões, corn relacão ans dadas levartados sobrt o use de biblielexas, a pesquise aponta para a necessidade de a escola assumir verdadelramerte seu papel de formadora de leitores, Intensificando sua aça en lod as as ciregôes que se ralacionam com o gostc pela leitura.

Ressalte-se que blblloteca escolar, embora se constilua err uril pspach te aquisic th e disseminacă $d$ e cultura e informaçäc, apresenta-se carente das condlç̄os adequadas para ofcrLar um scrviço citudúo, no sentido de que está irnedida de via. bilizar um processo de democratizaçẩo da Informaçấo ccm amdo acesso aos meios de cultura, uma vez cle a sla existência está condicionada úrica e excluslvamente à presença de acervo, e nủo à ofterlu de servicos capa ces de promover o acesso jos saberes registrados nos artefatos culturals que a blblloteca escolar deve dispcribillzar. 
Nessa abrangência, o Sistema CFB/CRB compreende que o trabalto da biblioteca escolar há de Ler como punte de pertida o con texto da escola, seu projeto pedagógico e a cultura geral que compõe o conjunto ce saberes que furdamertam e cão sentido ac mocis te vide $c$ à existêncie. de cada membro da comunicade escolar. Isto implica aralisa uma daca realldace, refletindo sobre as condiçōes existertes e prcver as formas alternativas de açăo para superar as cificuldades ou pare alcanciar os ctajclivos cesejadcs pela proposta pedagógica desenvolvida no âmbito da escola

0 gasto de numerário píblico, como jú dcslacudo, em simples acuisição e cistribuiçăo de acervo, principalntente composio de llvros, sem abranger a existèr. cia, orçanizacão e marutencăo de biblictecas fere o Interesse píblico, já que em última instàr. cia, esses recursos sajo cxtruicios dos cofres públicos a partir da

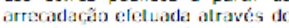
contribuinte, configurando-se em malharatacâo to patrimônio cultural, que falsamente está serdo construids, ncis a informuciồ nữo cumpre $0 \mathrm{GCu}$ polen cial de circulaçẫo, seja em termos sociuis uu geográficos ou melhorando o nivel de conheclmerto do alurado e cos educadores em geral.

Nais do que propor 0 exato mocelo de: bibliciecas escolares. as organlzações abalxo assinadas reivindicam o respeit aos prircíplos estabelecidos na Corstituição Federal (1988), ro yte tange ac dircito do cidadäo en ter acesso a um espaço no quel a informacion concretize SL papel social, cemocratizante vez cue ràn se pode oreterder que $c$ acevo não processadc de forma técrica, cientifica, atenda a cssu funçúc quc, por set soticl é garantia ca corstrução da cideadenia. E exelarrente, dipa-st de outro moco, a Infcrmaçẫo que se orcaniza, orcresca $f s$ dissemina, apćs receber o tratamerto adequado, que podera atender ac cidadüo cm amplo raio de demandas a níveis de comprecrisito.

Brasília, 20 de marco de 2000
Assinam o Manifesto:

Conselho Federal de Biblioteconomia

Conselho Regional de Biblioteconomia - La Regiäo

Conselho Regional de Biblioteconamia - 2a Regiäa

Conselho Regional de Biblioteconomia - $3^{\text {n Região }}$

Conselho Regional de Biblioteconomia - $4^{\circ}$ Regillo

Conselho Regional de Biblioteconomia - 5a Regiäo

Conselho Regional de Biblioteconamia - 60 Regiäa

Conselho Regional de Biblioteconomia - 7' Regiäa

Conselho Regional de Biblioteconomia - 8' Regillo

Conselho Regional de Biblioteconomia - 9d Regiäo

Conselho Regional de Biblioteconamia - 10 Regiäa

Conselho Regional de Biblioteconomia - $11^{\mathrm{A}}$ Regillo

Conselho Regional de Biblioteconomia - $12^{\circ}$ Regityo

Conselho Regional de Biblioteconomia - $13^{\text {d }}$ Regiäo

Conselho Regional de Biblioteconamia - $14^{a}$ Regiäa

Conselho Regional de Biblioteconomia - 15 Regito

\section{ATIVIDADES A SEREM REALIZADAS NO DIA 23 DE ABRIL DE 2009 MOVIMENTO EM PROL DA BIBLIOTECA ESCOLAR}

Consultar os Ascessores luricicos par impetrar açổes junto acs Ministérios Públicos Fstaduais f Muricloals em funçajo da criaçãc de lels para Implantaçjo de cspaçcs de leltura (blbllcteca, sala de leitura, ocntos de leitura) ser a presença de bibliotecários. Responsabilidade: Corseltho Regional e Correlho Feteral.

2. Elabcraçăo de um manifesto a favor ca biblioteca escolar a ser publicado en tocos os jornais

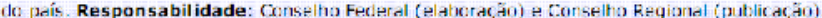

3. Distribulçấc do folder do Projeto Mobllizador para todos os conselhos estaduals e municipais de educação, se possivel ccm a presença de membros do Regional. Responsabilidade: Conselhc Reciond.

4. Eleger uma ficura pública para apoiar o movirnentc. Responsabilidade: Corselho Federal

5. Levinlar $e$ expor as hotes prálicas existerles no país. Responsabilidade: Cunkelho Fetdera con apolo cos Corselhos Regionals.

6. Buscar marcar au. diẻncias pútlicas nas Assembléias legislativas Fstaduaise na Cârara Federa visanco discutir os aspcetcs da nccessi dade de implartaçajo da biblicteca cscolar. Responsabilidade: Conselho Federal (ámbito nacional) Corselhos Estaduais (ámbitc de caca jurisdi(c) 201$)$.

7. Conclamar as escolas para reallzarem um evento, ro da, para lançamerto do Manifesto em cada regiăo. Responsabilidade: Conselho Regional (ámbito de cada jurisciģäc);

8. Elaborar a divulgar amplamente um boletim clctrório especial scbre a temático. Responsabilidade: Conselho Federal (elaboraçăc do toletin Conselhcs Reçicnais (distribuição do bcle(im).

9. Olvulgar c projetc moblilzador junto a tcdos partidos politicos. Responsabilidade: Corselhc

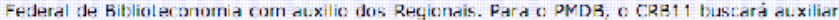
no agendamerto da reunläo 
Assunto:

CARTA DE BRASILIA EM DEFESA DA BIBLIOTECA ESCOLAR

Data:

$$
\text { Tue, } 12 \text { Jun } 2007 \text { 11:20:53 -0300 }
$$

CARTA DE BRASILIA DO SISTEMA CONSELHO FEDERAL E REGIONAIS DE BIBLIOTECONOMIA EM DEFESA DA BIBLIOTECA ESCOLAR

Segundo a UNESCO, a biblioteca escolar é o espaço que “[...] promove serviços de apoio à aprendizagem e livros aos membros da comunidade escolar, oferecendo-lhes a possibilidade de se tornarem pensadores críticos e efetivos usuários da informação, em todos os formatos e meios".

Acompanhamos com preocupação o momento por que passa a educação no Brasil, com baixos índices de aprendizagem dos alunos, demonstrando que eles não possuem competência em leitura e escrita. Diante desse fato, acreditamos que se as instituições de ensino investirem na criação de espaços de bibliotecas bem equipadas, com acervos que atendam o projeto político pedagógico das escolas e administradas por profissionais Bibliotecários, está triste realidade poderá sofrer significativa transformação.

Alguns documentos elaborados pelo Ministério da Educação apontam para a importância da biblioteca na prática da leitura e escrita, um dos maiores problemas de nossa educação atualmente. Podemos citar os Parâmetros Curriculares Nacionais (PCN's), que, no módulo de Língua Portuguesa, cita a biblioteca como um espaço apto a influenciar e incentivar a prática da leitura e escrita.

Recomenda, ainda, que seja um local de fácil acesso aos livros e materiais disponíveis e que a escola estimule a frequência ao espaço, contribuindo assim para tal a prática.

Nos debates do programa Salto para o Futuro, os especialistas que participam das discussões sobre alfabetização e letramento, apontam a 
biblioteca escolar como espaço de excelência na aquisição de leitura e escrita.

O Plano Nacional de Biblioteca Escolares (PNBE) do MEC, distribui acervos para bibliotecas escolares. Se as escolas não possuem bibliotecas e muito menos bibliotecários, como está sendo dinamizado este acervo?

A Lei 10.172 de 2001, que aprova o Plano Nacional de Educação, determina que as escolas de ensino fundamental e médio, para o seu funcionamento, deverão ter um padrão mínimo nacional de infra-estrutura, compatível com o tamanho dos estabelecimentos e com a realidade regional. Deverão ter espaço para biblioteca e atualização e ampliação do acervo das existentes.

Determina ainda, que a partir do segundo ano da vigência deste plano, o MEC só deverá autorizar a construção e funcionamento de escolas que atendam aos requisitos e infra-estrutura, entre estes, a construção de uma biblioteca.

É de responsabilidade do MEC a fiscalização e cumprimento da Lei, assim como não permitir que novas escolas sejam abertas sem que possuam uma biblioteca.

A qualidade da educação acha-se intimamente ligada à oferta, pela escola, de meios, instrumentos, equipamentos e suporte para que o educando integre-se à cultura, assimile, processe e produza enquanto sujeito do processo civilizatório, sujeito da construção da cidadania. Este o sentido das disposições do art. 205 da carta magna, garantidores da universalização da educação, como um direito de todos e dever do Estado, visando seu preparo como pessoa, para o exercício da cidadania e sua qualificação para o trabalho.

Também, a principiologia que sedimenta a ministração do ensino no pais, consoante explicitação do art. 206 do texto constitucional, identifica bases na igualdade de condições de acessibilidade a escola; liberdade de aprender, ensinar, pesquisar e divulgar o pensamento, a arte e o saber. Em todos os pontos do capítulos do capítulo 11l, Seção 1 "da Educação", explicita-se o compromisso do estado com a qualidade da educação. A Lei no 4.084, de 30 de junho de 1962, dispõe sobre a profissão de Bibliotecário e regula seu exercício. Em seu Art. 6 o determina "[...] que, entre as 
atribuições dos Bacharéis em Biblioteconomia, estão a organização, direção e execução dos serviços técnicos de repartições públicas federais, estaduais, municipais e autárquicas e empresas particulares".

O exercício dessas funções por leigo constitui uma infração a legislação vigente e, principalmente, fere o direito constitucional do cidadão em receber a prestação de serviços por profissional especializado e habilitado, consoante disposição do inciso XIII do artigo $5^{\circ}$. da Constituição Federal, que dispõe sobre a liberdade de exercício de trabalho, ofício ou profissão, desde que atendidas as qualificações profissionais que a lei estabelecer.

Ressalte-se que biblioteca escolar, enquanto ente representativo de um espaço de aquisição e disseminação de cultura e informação, apresentase carente de um serviço cidadão, no sentido de que não se pode viabilizar um processo de democratização da informação sem amplo acesso aos meios de cultura.

Entendemos que a informação contida em uma biblioteca, uma vez processada por um profissional bibliotecário, é a que mais diretamente atingirá o destinatário da mesma: o usuário com quem interage, o que traz a ele suas demandas.

É exatamente no espaço da biblioteca escolar que a informação é processada com vistas à disseminação imediata ao usuário discente - e ao docente também; ao acesso adequado. É neste espaço que a informação concretiza seu papel social, democratizante, vez que não se pode pretender que o acervo não processado de forma técnica, cientifica, atenda a essa função que, por ser social é garantia da construção da cidadania. É exatamente, repita-se, a informação que se organiza, processa e se dissemina após receber o tratamento adequado, que poderá atender ao cidadão em amplo raio de demandas e níveis de compreensão.

Este, portanto, o real papel do Bibliotecário na construção da educação cidadã.

Brasília, 23 de março de 2007.

Conselho Federal de Biblioteconomia

Conselho Regional de Biblioteconomia $-1^{\text {a }}$ Região

Conselho Regional de Biblioteconomia - $2^{\text {a }}$ Região

Conselho Regional de Biblioteconomia $-3^{\mathrm{a}}$ Região 
Conselho Regional de Biblioteconomia $-4^{a}$ Região Conselho Regional de Biblioteconomia $-5^{\text {a }}$ Região Conselho Regional de Biblioteconomia $-6^{a}$ Região Conselho Regional de Biblioteconomia $-7^{a}$ Região Conselho Regional de Biblioteconomia $-8^{a}$ Região Conselho Regional de Biblioteconomia $-9^{a}$ Região Conselho Regional de Biblioteconomia - 10 Região Conselho Regional de Biblioteconomia - $11^{\text {a }}$ Região Conselho Regional de Biblioteconomia - 12 $2^{\mathrm{a}}$ Região Conselho Regional de Biblioteconomia - $13^{\text {a }}$ Região Conselho Regional de Biblioteconomia - 14 ${ }^{\mathrm{a}}$ Região

Recebido em: 06/02/12. Aprovado em: 02/04/13.

Title: Certain senses of school library: effects of repetition and displacement

Authors: Ludmila Ferrarezi; Lucília Maria Sousa Romão Abstract: Beginning with the theoretical-analytical foundation of the French Discourse Analysis, specially the concepts proposed by the philosopher Michel Pêcheux, we investigated which senses were mobilized in the composition of discourses about the school library that circulate in three official documents, elaborated by the class organs of Librarianship and made available in the internet. For such, we initially presented the concepts of memory, ideology, discursive formation, imaginary formation and heterogeneity that helped us to investigate the discursive operation present in our corpus. On this subject we observed in our analysis how the discursive memory causes some denotations already mentioned about the school library to be updated and, at the same time, as they can be ruptured, installing the different.

Keywords: Discourse. Memory. Scholar Library. Librarianship.

Título: Ciertos sentidos de biblioteca escolar: efectos de repetición y desplazamiento

Autores: Ludmila Ferrarezi; Lucília Maria Sousa Romão

Resumen: A partir del fundamento teórico-analitico del Análisis del Discurso de línea francesa, especialmente los conceptos propuestos por el filósofo Michel Pêcheux, nosotros investigamos cuales sentidos fueron movilizados en la constitución de los discursos sobre 
la biblioteca escolar que circulan en tres documentos oficiales, elaborados por los órganos de clase de la Biblioteconomía y puestos a disposición en la Internet. Para tanto, nosotros presentamos inicialmente los conceptos de memoria, ideología, formación discursiva, formación imaginaria y heterogeneidad, que nos ayudaron a investigar el funcionamiento discursivo presente en nuestro corpus. En él, observamos, a través de nuestros análisis, como la memoria discursiva hace con que algunos sentidos ya dichos sobre la biblioteca escolar sean actualizados y, al mismo tiempo, como ellos pueden ser rotos, instalando lo diferente.

Palabras-clave: Discurso. Memoria. Biblioteca escolar. Biblioteconomía. 